\title{
APPLICATION OF FLAP-GATE-TYPE RISING SEAWALL TO THE PORT OF MUYA
}

\author{
Katsuhiko KOIZUMI ${ }^{1}$, Kazunori TATEWAKI ${ }^{2}$, Yoshihiro HOSOKAWA ${ }^{3}$, \\ Tomohiro HIRAIKE ${ }^{4}$ and Masato YASUDA ${ }^{5}$ \\ ${ }^{1}$ Member of JSCE, Takamatsu Research and Engineering Office for Port and Airport, Ministry of Land, \\ Infrastructure, Transport and Tourism, Shikoku Regional Development Bureau \\ (Harbor united office 3F, 1-30, Asahi-sinmachi, Tamatsu-city, Kagawa 760-0064, Japan) \\ E-mail: koizumi-k88s3@mlit.go.jp (Corresponding Author) \\ ${ }^{2}$ (Former staff) Takamatsu Research and Engineering Office for Port and Airport, Ministry of Land, Infrastructure, \\ Transport and Tourism, Shikoku Regional Development Bureau \\ (Harbor united office 3F, 1-30, Asahi-sinmachi, Tamatsu-city, Kagawa 760-0064, Japan) \\ ${ }^{3}$ Member of JSCE, Marine Environment and Engineering Division, Ministry of Land, Infrastructure, \\ Transport and Tourism, Shikoku Regional Development Bureau \\ (Takamatsu Sunport Godochosha 8F,33-3, Sunport, Tamatsu-city, Kagawa 760-8554, Japan) \\ E-mail: hosokawa-y88s3@mlit.go.jp \\ ${ }^{4}$ HONMA-Corporation Co., Ltd \\ (3300-3 Sanno-cho, Nishiminatomachi-dori,Chuo-ku, Niigata-city, Niigata 951-8650, Japan) \\ E-mail: tomohiro-hiraike@honmagumi.co.jp \\ ${ }^{5}$ ECOH Corporation, Tokyo, Japan (2-6-4, kitaueno, Taitou-ku, Tokyo 110-0014, Japan) \\ E-mail: yasuda@ecoh.co.jp
}

\begin{abstract}
Based on the basic technology established in the knowledge of flap- gate-type breakwater, the newly developing flap-gate-type rising seawall was applied to improve the coast protection facility of Muya port, Tokushima, Japan. It has been put to practical use to overcome various problems due to the on-land installation. It is a new type of seawall, using the buoyancy during inundation at the time of tsunami, tidal wave/storm surge, in which the gate leaf turns upright and falls without power/manual operation. In this paper, the basic idea of design and maintenance based on the applicability study of flap-gate-type rising seawall to the Port of Muya is presented.
\end{abstract}

Key Words : flap-gate seawall, rising seawall, tsunami and storm surge, technical manual, maintenance

\section{INTRODUCTION}

The tsunami that came with the 2011 Off the Pacific Coast of Tohoku Earthquake claimed the lives of many operators engaged in closing landlocks and water gates ${ }^{1)}$. For this reason, methods to ensure safe and sure closure of landlocks and water gates have been undertaken requiring their consolidation and abolition, regular closure, and automation or remote operation.

The flap-gate-type rising seawall is based on the basic technology established in the research on the flap-gate-type breakwater proposed by the Coastal Zone Water Gate Study Group (inaugurated based on the "New Century Port Vision," FY 2000, Ministry of Land, Infrastructure, Transport and Tourism (MLIT)), and overcomes various technical problems associated with installation on land. This technology was applied practically to the Improvement Project of the Muya Port Coastal Protection Facilities (Tokushima Prefecture, Japan).

The flap-gate-type rising seawall is a new type of landlock that automatically closes seawall openings by utilizing the buoyancy of the gate leaf at the time of inundation by a tsunami or storm surge to turn the gate upright without power or manual operation, and then lower the gate after the water retreats ${ }^{2}$. The outline features are shown below.

- Operators are not exposed to danger, as direct human operation is not necessary.

- The gates operate even during a power failure because electric power, etc., are not required.

- The landlock can be used as an escape route until just before a tsunami arrives.

- In case of a tsunami generated by a distant earthquake or predicted storm surge, the gate can be raised manually in a simple manner in advance.

This report presents an outline of the basic con- 
cepts of the design, construction, and maintenance of the flap-gate-type rising seawall to be installed in coastal facilities and port and harbor facilities based on the concrete study of application at the Muya Port Coast. A "Technical Manual on Flap-GateType Landlock for Ports and Coastal Zones" ${ }^{2)}$ was also prepared based on this knowledge.

\section{OVERVIEW OF FLAP-GATE-TYPE RISING SEAWALL ${ }^{2)}$}

\section{(1) Principle of operation}

In a normal forward flow, a conventional flap gate operates as shown by the blue line in Fig. 1. The principle of operation is described in Reference 3), which states that flap gates "are used in cases where the purpose is to prevent backflow in a rectangular water channel, and opening/closing are performed by rotation in the direction of water pressure, centering around a hinge at the top of the gate leaf." In contrast, the flap-gate-type rising seawall described in this paper has a bottom hinge structure. Under normal conditions, the gate is lodged and stored near the ground surface to secure pedestrians and vehicular traffic. However, during inundation by a tsunami or storm surge, the gate is raised by its natural buoyancy, turns to the upright position around its rotational axis, and blocks inundation to the hinterland by the tsunami or storm surge ${ }^{4)}$.

\section{(2) Outline of structure}

As shown in Fig. 2 (bottom), the flap-gate-type rising seawall is kept in a lodged position by the selfweight of the gate leaf. The structure consists of the foundation slab that stores the gate, sidewalls that secure water-tightness when the gate is raised by the buoyancy accompanying inundation, tension rods

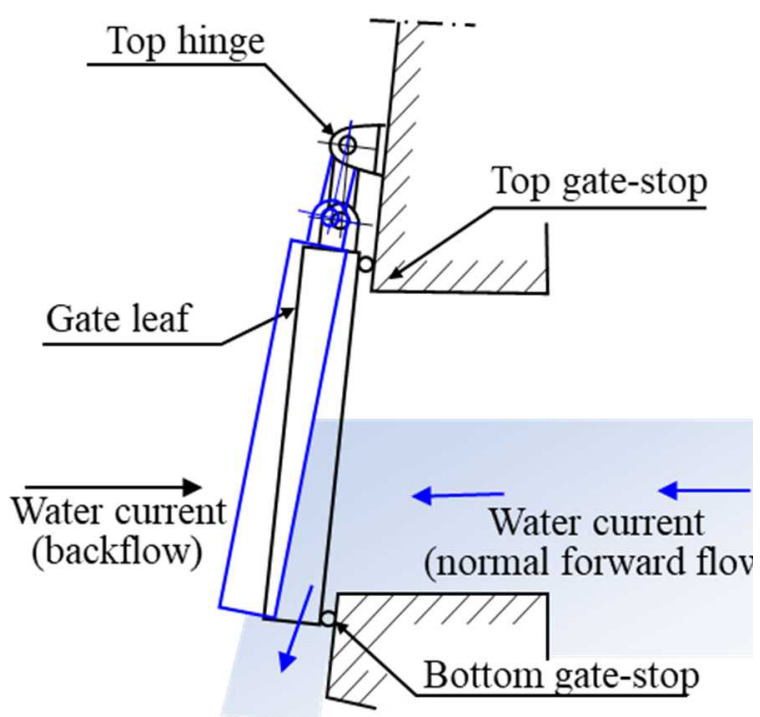

Fig. 1 Conventional flap gate. that transmit water pressure differences, wave force, etc., to the foundation, and a bottom hinge, which functions as the axis of rotation. Appropriate drainage facilities are also provided because the gate leaf will obstruct pedestrians and vehicular traffic if it rises due to inundation by heavy rain, etc.

\section{DESIGN OF FLAP-GATE-TYPE RISING SEAWALL}

(1) Design fundamentals ${ }^{2}$

a) Component materials and design criteria and design techniques

In the study of the applicability of the flap-gatetype rising seawall to Muya Port, the performance requirements and performance criteria for tsunamis, storm surges, and earthquakes were studied. Based on the results, the performance verification procedure, partial factors, and structural analysis factors, loads to be considered in design and main materials to be used were set.

Because the flap-gate-type rising seawall is used as a coastal protection facility or port facility, its design
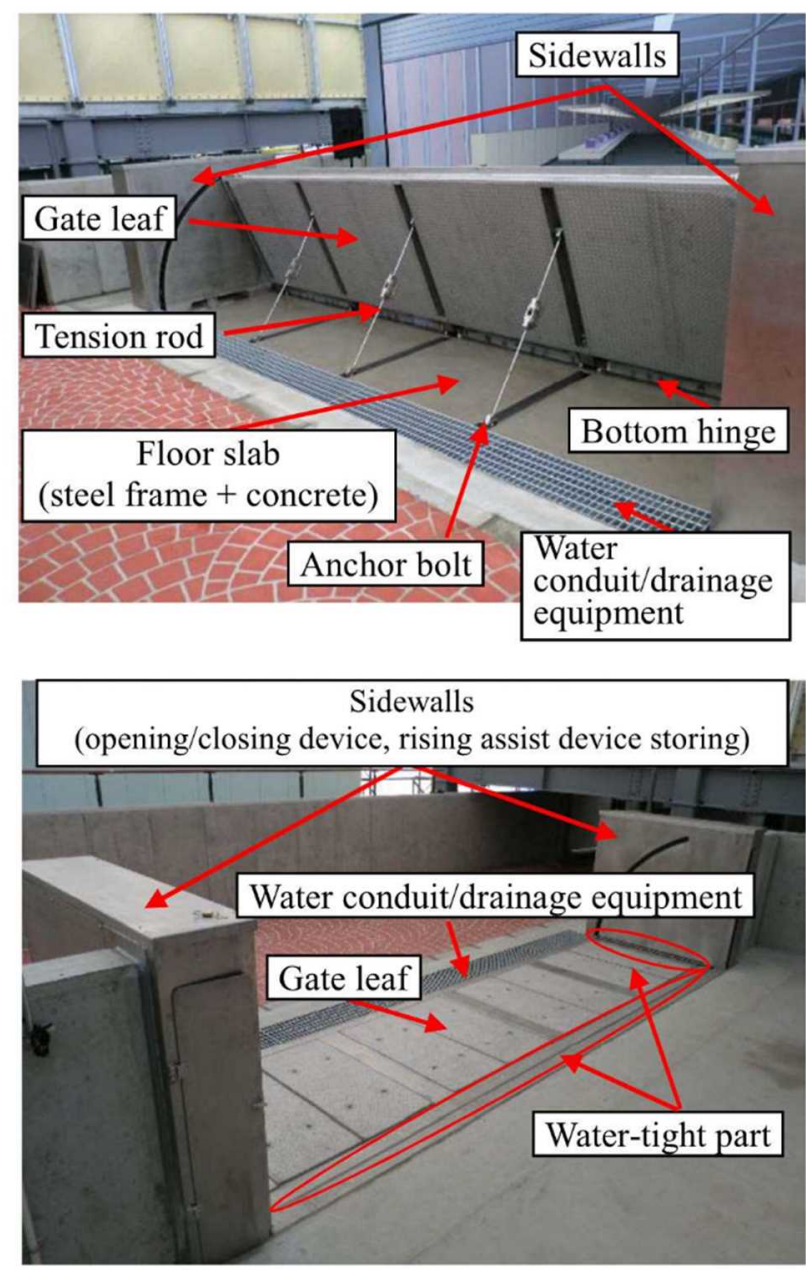

(Top: raised condition, bottom: lodged condition)

Fig. 2 Flap-gate-type rising seawall ${ }^{2}$. 
must conform to the Technical Standards and Commentaries for Shore Protection Facilities ${ }^{5)}$ and Technical Standards and Commentaries for Port and Harbour Facilities in Japan ${ }^{6}$, respectively. However, the main applicable standard for the design of the superstructure, including the gate leaf, sidewalls, slab, and other parts, which are classified as mechanical equipment, is the Technical Standards and Commentaries for Dams and Weirs (Draft) ${ }^{7)}$ (Table 1).

\section{b) Performance requirements and performance}

\section{criteria}

Because the purpose of the flap-gate-type rising seawall is to close the opening in a seawall by turning the gate upright automatically without drive force when a tsunami or storm surge attacks, thereby preventing inundation to the hinterland, it is necessary to secure the following required performances against tsunami, storm surges, and earthquakes:

- Continuous use must be possible, without impairing the function of the structure as a landlock against frequent tsunamis and storm surges. Concretely, in order to maintain its protective function, the crest height of the facility after an earthquake must not be lower than the crest height determined by the permissible wave overtopping rate or tsunami height and the flap-gate-type rising seawall shall float and rise due to the rise in the water level accompanying a tsunami or storm surge, even under the condition that the seawall has been displaced to some extent by the earthquake preceding the tsunami (usability against tsunami).

- For tsunamis of the largest class, which occur extremely less frequently, aim at a "resilient structure" with collapse resistance against such tsunamis. However, the design may also consider usability, restoration, and safety, depending on the performance requirements of the facility.
For the above-mentioned two items, a study in combination with a subsequent tsunami may be required in some cases due to the positional relationship between the location of the earthquake hypocenter (tsunami source) and the location of flap-gatetype rising seawall installation, and the relationship between Level 1 and Level 2 earthquake ground motion, and the earthquake preceding a tsunami.

- In the case of Level 1 earthquake ground motion, continuing use shall be possible without impairment of the soundness of the facility as a landlock.

- In the case of Level 2 ground motion preceding a tsunami (subduction-zone earthquake), the function of the facility as a landlock shall not be impaired.

- In the case of Level 2 ground motion not preceding a tsunami (inland-type earthquake), damages shall be minor and quick recovery shall be possible.

\section{(2) Design of substructure 2)}

\section{a) Basic items and combinations of loads}

In the substructure, the functions of storing the lodged gate leaf and supporting traffic loads are required under normal conditions and the function of stable support of the hydrodynamic force acting via the raised gate is required during a tsunami or storm surge. Therefore, the substructure is selected considering the topographic and geological conditions, the features of the structure, construction conditions, environmental conditions, etc., and the type of foundation structure (spread foundation or pile foundation) shall be studied considering the ground conditions. It is also necessary to study stability against earthquakes; particularly the phenomenon of liquefaction, since the flap- gate-type rising seawall is basically functional during a tsunami attack.

With the above, in the design of the substructure, it is necessary to verify safety for the permanent situ-

Table 1 Structural members and design standards and design methods ${ }^{2)}$.

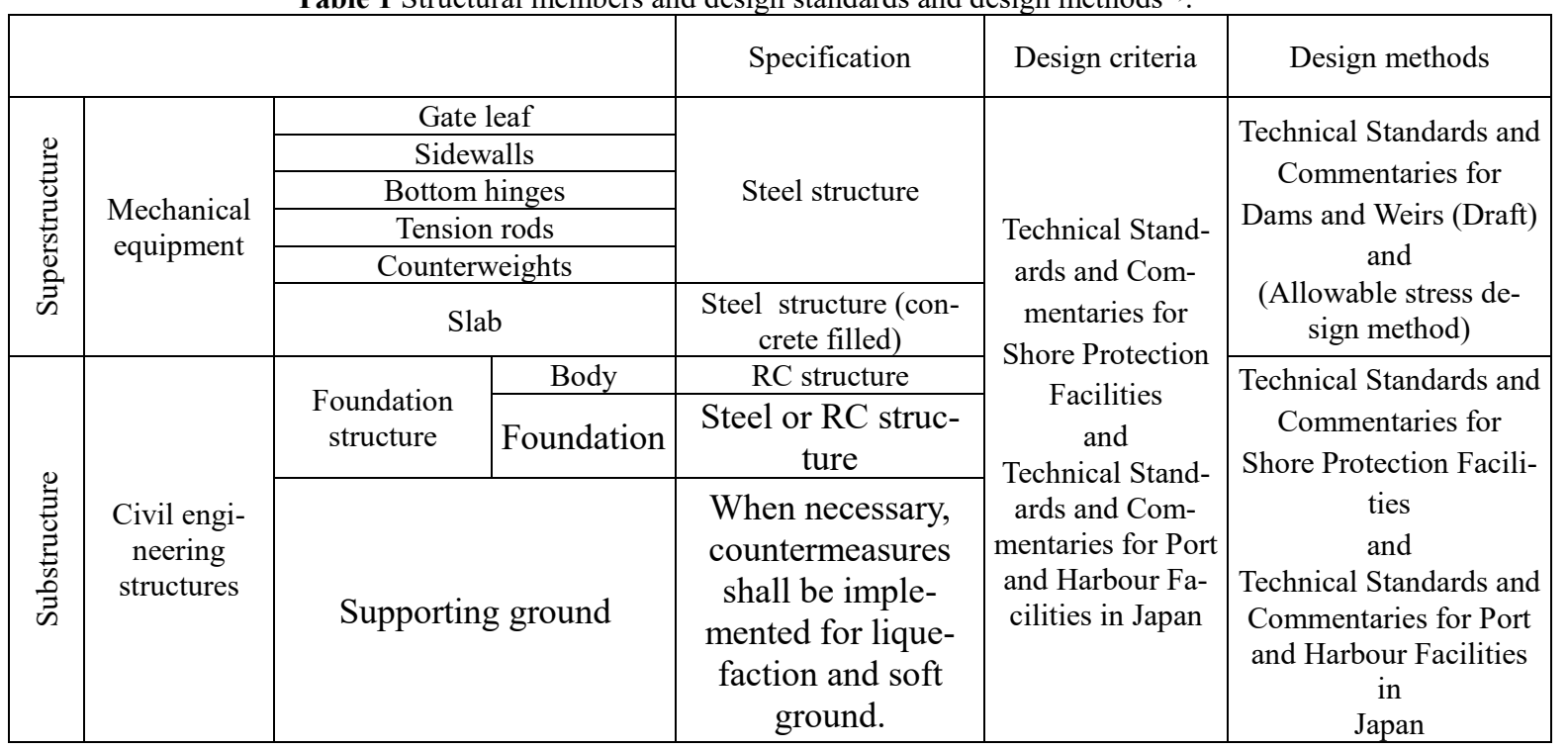


ation (normal conditions), variable situations (Level 1 earthquake, wave action due to storm surge), accidental situations (Level 2 earthquake (subduction zone earthquake), action of tsunamis with high frequency of occurrence, action of a tsunami of the largest class, and when necessary, earthquakes and aftershocks preceding a tsunami). The combinations of loads used in the design are shown in Table 2. Here, we will consider the self-weight as dead load, the weight of vehicles traveling over the lodged gate leaf as surcharges, and the collision force of tsunami flotsam (floating wreckage drifting in a tsunami) as a collision load ${ }^{2}$. As the hydrostatic pressure during a tsunami, the hydrostatic pressure at the maximum water depth during the tsunami attack is given ${ }^{2)}$. For wave pressure, the wave during a storm surge is given. During aftershocks, the hydrostatic pressure caused by a tsunami and the dynamic water pressure calculated by the simplified Westergaard's approximate formula as the effect of the earthquake were considered ${ }^{2}$. The design seismic intensity when calculating the dynamic water pressure followed the Technical Standards and Commentaries for Dams and Weirs (Draft) ${ }^{2)}$. In addition, in the case of the Muya Port

Table 2 Combinations of loads used in the design of substructure ${ }^{2)}$.

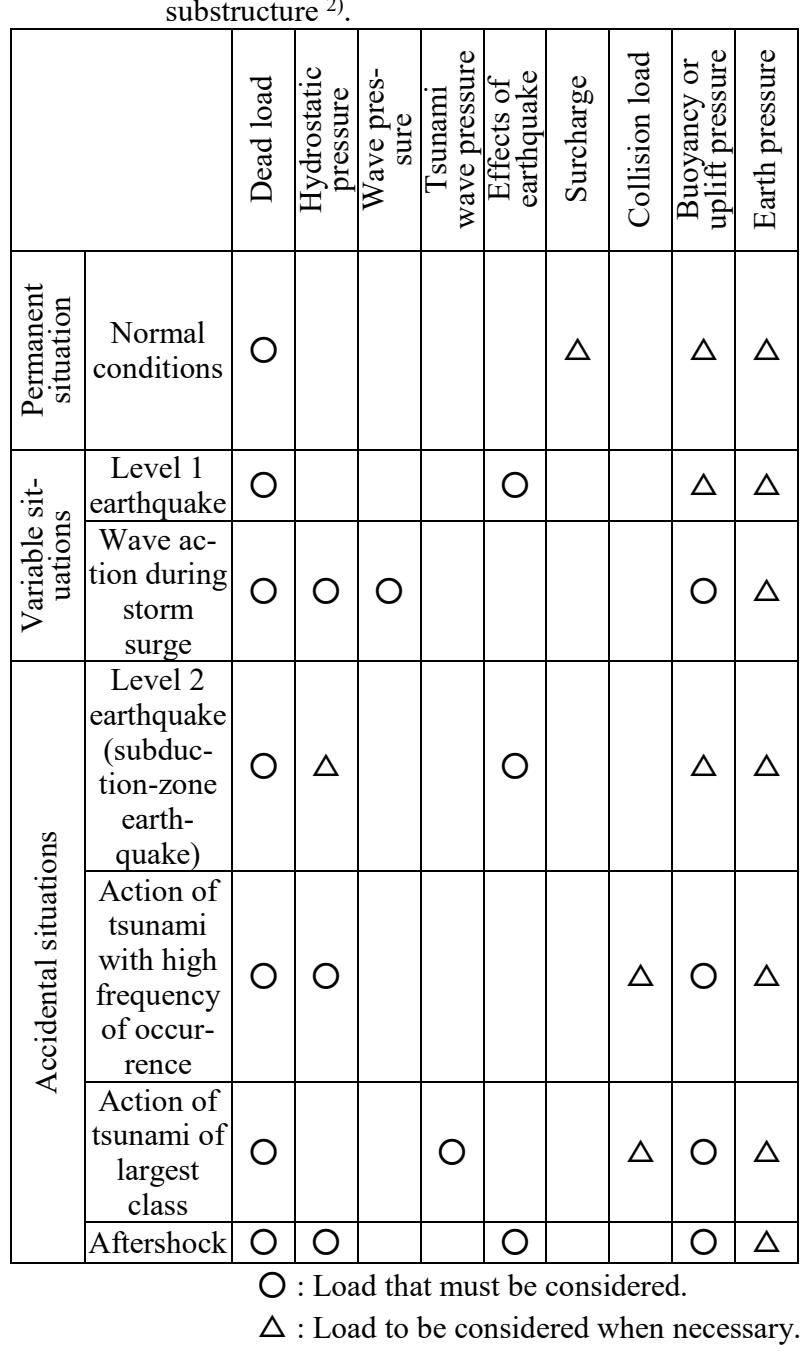

Coast Project, a steel pipe pile foundation was adopted as the substructure. The foundation was designed so that the angle of inclination of flap- gate- type rising seawall because the seismic motion preceding a tsunami becomes smaller than $3^{\circ 8)}$.

\section{b) Design of water conduit/drainage structure}

The water conduit/drainage structure is installed to convey water precisely to the bottom side of the gate leaf during inundation in order to float and raise the gate quickly, and also to prevent unnecessary flotation due to rainwater, etc., stagnating under the gate when the top side of the gate is used as the road surface under normal conditions. Structurally, there is one type in which gratings are installed in front and on the sides of the gate, and another type in which drainage pipes and a catch basin are installed in the slab under the gate. The grating type structure was adopted at the Muya Port Coast.

\section{(3) Design of superstructure ${ }^{2)}$}

\section{a) Basic items and combinations of loads}

The design of the mechanical equipment comprising the superstructure, such as the gate leaf and the sidewalls, slab, and other parts is based on the Technical Standards and Commentaries for Dams and Weirs (Draft) ${ }^{7}$. The installation positions and clear span, which are basic items, must be set appropriately considering the usage of the facility. The site height and effective height must be set considering the Regional Disaster Prevention Plan, the influence of ground subsidence, and the height of the road connected by the gate and the adjoining seawall, and the design inundation height in case of a tsunami or storm surge. In the design of the superstructure, it is also necessary to verify safety for the raised condition (fully closed condition; condition of the gate under maximum wave pressure), and in the lowered condition (fully open condition; the condition in which the gate is stored in a position that does not obstruct road traffic). The combinations of loads used in the design of these respective conditions are shown in Table 3.

\section{b) Tension rods}

Tension rods are members that distribute the loads acting on the gate leaf and transmit these loads to the foundation structure. The load distribution effect makes it possible to reduce the thickness of the gate framework, which in turn increases the web buckling strength of the longitudinal main girders and horizontal main girders against wheel load. As a result of this, the self-weight of the gate leaf can be reduced, and the weight of the rising assist device and sidewalls can also be reduced. Figure 3 shows the relationship diagram for the weight of steel materials with/without the use of tension rods excerpted from Reference ${ }^{2)}$, with added examples of the rough design of flap-gate-type rising seawalls by the authors. 
Table 3 Combinations of loads used in the design of superstructure ${ }^{2)}$.

\begin{tabular}{|c|c|c|c|c|c|c|c|c|c|c|}
\hline When lodged & 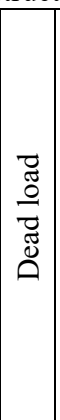 & 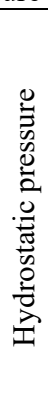 & 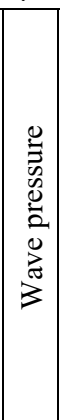 & 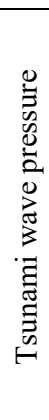 & 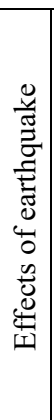 & 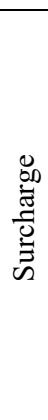 & 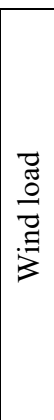 & 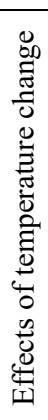 & 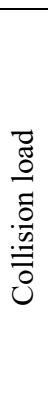 & 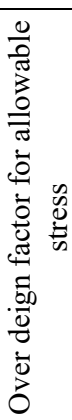 \\
\hline $\begin{array}{c}\text { Normal con- } \\
\text { ditions }\end{array}$ & 0 & & & & & 0 & $\triangle$ & $\triangle$ & & 1.0 \\
\hline $\begin{array}{l}\text { During earth- } \\
\text { quake }\end{array}$ & 0 & & & & 0 & & & & & 1.5 \\
\hline
\end{tabular}

\begin{tabular}{|c|c|c|c|c|c|c|c|c|c|c|c|}
\hline \multicolumn{2}{|c|}{ When raised } & 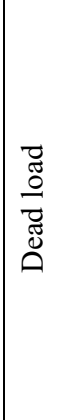 & 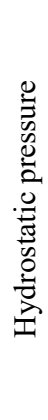 & 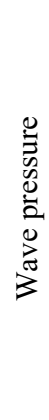 & 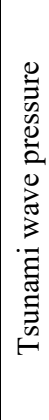 & 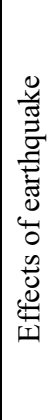 & 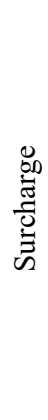 & 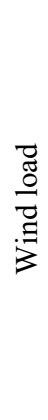 & 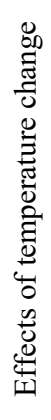 & 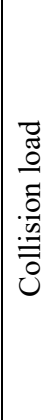 & 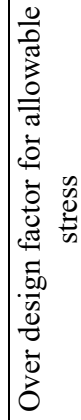 \\
\hline \multirow{3}{*}{ 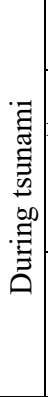 } & $\begin{array}{c}\text { During } \\
\text { tsunami } \\
\end{array}$ & 0 & $\mathrm{O}$ & & & & & & & & 1.0 \\
\hline & \begin{tabular}{|c|} 
Maxi- \\
mum tsu- \\
nami \\
wave \\
force \\
\end{tabular} & 0 & & & 0 & & & & & & 1.5 \\
\hline & \begin{tabular}{|c} 
(Tsu- \\
nami \\
overtop- \\
ping)
\end{tabular} & 0 & & & 0 & & & & & & (1.7) \\
\hline \multicolumn{2}{|c|}{ Storm surge } & 0 & 0 & 0 & & & & & & & 1.0 \\
\hline \multicolumn{2}{|c|}{ Collision } & 0 & $\mathrm{O}$ & & $\triangle$ & & & & & 0 & 1.5 \\
\hline \multicolumn{2}{|c|}{ Aftershock } & 0 & 0 & & & 0 & & & & & 1.5 \\
\hline \multicolumn{2}{|c|}{$\begin{array}{l}\text { When raised } \\
\text { without wa- } \\
\text { ter }\end{array}$} & 0 & & & & & & $\triangle$ & & & 1.0 \\
\hline
\end{tabular}

In this figure, the $\square$ and $\bigcirc$ symbols show the actual results with and without tensions rods, respectively, as extracted from Reference ${ }^{2)}$. The horizontal axis represents the clear span of the gate and the vertical axis shows the steel weight per unit area of the gate, which was calculated by dividing the weight of steel materials used in the flap-gate-type rising seawall (excluding the foundation) by the area of the gate leaf. From these results, when the clear span is less than $5 \mathrm{~m}$, there is no large difference in the steel weight per unit area of the gates with and without the tension rods, but when the clear span is $5 \mathrm{~m}$ or larger but less than $10 \mathrm{~m}$, the steel weight per unit area of

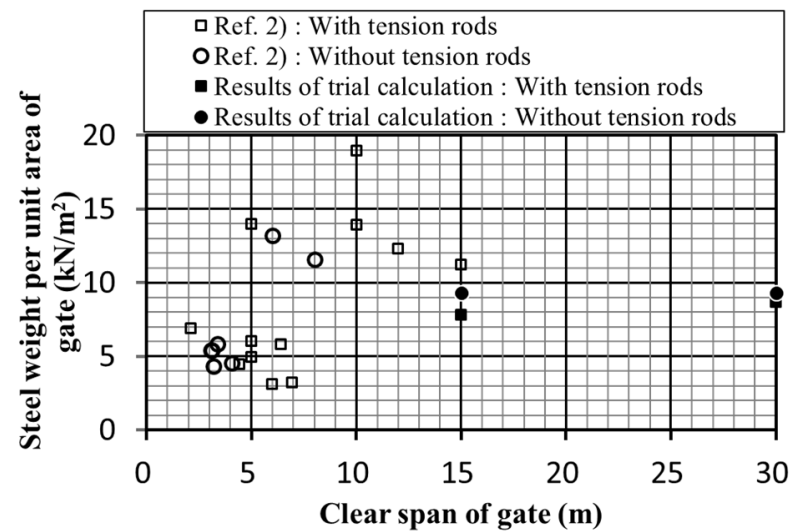

Fig. 3 Relationship between steel weight and clear span of the gate with/without tension rods (Reference 2, Fig.-Commentary 4.10.1, with additions by the authors).

the gate tends to be smaller without the tension rods. There are no examples of gates without tension rods when the clear span exceeds $8 \mathrm{~m}$. From this, it can be surmised that a structure with tension rods is economically advantageous when the clear span of the gate exceeds $8 \mathrm{~m}$. In the trial calculations by the authors, trial calculations were made for flap-gate-type rising seawalls with an effective height of $4.1 \mathrm{~m}$ and a clear span of $15 \mathrm{~m}$ or $30 \mathrm{~m}$, and the steel weight of those structures with and without tension rods were compared. All conditions except for the use of tension rods were the same. In the results of the trial calculations by the authors, the steel weight per unit area was smaller with the tension rods ( $\boldsymbol{\square})$ than without the tension rods ( ) . Based on these results as well, it is suggested that the use of tension rods is economically advantageous when the clear span exceeds $8 \mathrm{~m}$.

In case a tension-rod-type structure is adopted, it is necessary to consider the following points: ${ }^{2)}$

- The number and size of the tension rods should be determined appropriately to secure adequate strength for the water pressure acting on the gate.

- The installation positions should be decided depending on the relationship between the rising angle and the water level to avoid the direct effect of collision by drifting tsunami wreckage, etc.

- The structure and layout must not interfere with the raising and lowering operation of the gate.

- Although the water pressure acting on the gate acts approximately equally as a distributed load, because the load is divided among multiple tension rods, it must be possible to adjust the structure to avoid any remarkable differences in the distributed force of the individual tension rods.

\section{c) Rising assist device}

If the gate leaf of a flap-gate-type landlock is raised by buoyancy alone, the raising speed must increase from a condition of zero speed and rising will stop abruptly when rising is completed. Therefore, it was necessary to address concerns regarding the higher 
cost of a design that considered impact force and safety issues due to sudden lowering operation. A "rising assist device" (Fig. 4) was adopted to solve these problems. This device consisted of a counterweight, wire rope, and sheave (pulley).

At the start of flotation, the self-weight of the counterweight of the rising assist device acts in the upward direction, providing a rising assistance force. While rising is in progress, the function of the selfweight of the counterweight switches from rising assistance force to braking force. When rising is completed, the weight of the counterweight acts in the gate lowering direction, and thus becomes a braking force (Fig. 5, Fig. 6). It is necessary to design this rising assist device so that it will raise the gate rapidly, and will also absorb the impact when rising is completed. The concrete design procedure is as follows:

1) First, design a layout in which the sheave is stored in the sidewall.

2) Next, decide the weight of the counterweight. The weight of the counterweight is decided to secure a margin of $25 \%$ or more in the water depth at which gate rising (flotation) starts, considering the self-weight of the gate leaf and the sliding resistance of the water-tight rubber. That is, the weight is decided so that flotation will start at a water depth $<75 \%$ of the gate thickness.

3) Confirm that the crown of the gate leaf is always higher than the water surface during the process of water level rise. If this requirement cannot be satisfied, review the position of the sheave, and redesign the rising assist system.

Theoretically, the angle at which the counterweight changes from rising assistance force to braking force is decided by the sheave layout conditions. Therefore, if the sheave is stored in the sidewall, the angle at which the counterweight changes from rising assistance force to braking force is frequently around $45^{\circ}$. In Fig. 5, which shows the case of the Muya Port Coastal Protection Project, the moment of buoyancy increases gradually as the water level rises, but the moment of the counterweight decreases and changes to a braking force, with zero crosses occurring at $44.312^{\circ}$. The moment of resistance by the side water-

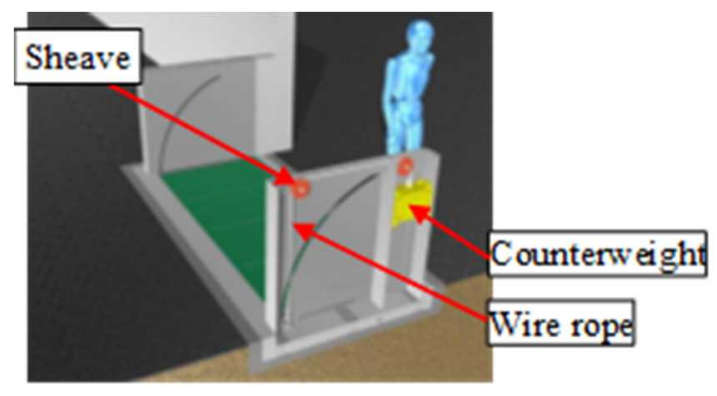

Fig. 4 Basic structure of rising assist device ${ }^{2)}$. tight rubber shown in Fig. 5 is the moment in the rising process and acts in the opposite direction in the lowering process. Thus, a simple yet highly reliable operation is possible by geometrically arranging the sheave and using a wire rope for turning operation of the gate leaf, utilizing a counterweight and the bottom hinge as the axis of rotation.

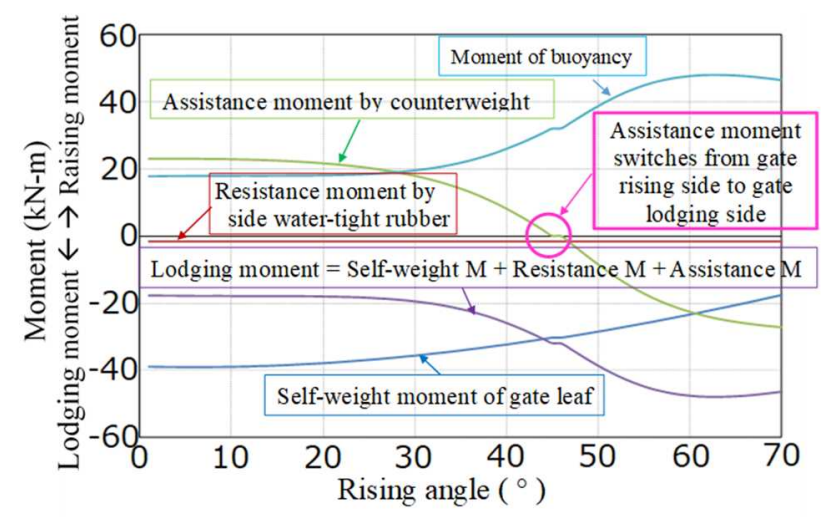

Fig. 5 Relationship of gate rising angle and overturning moment of gate self-weight.
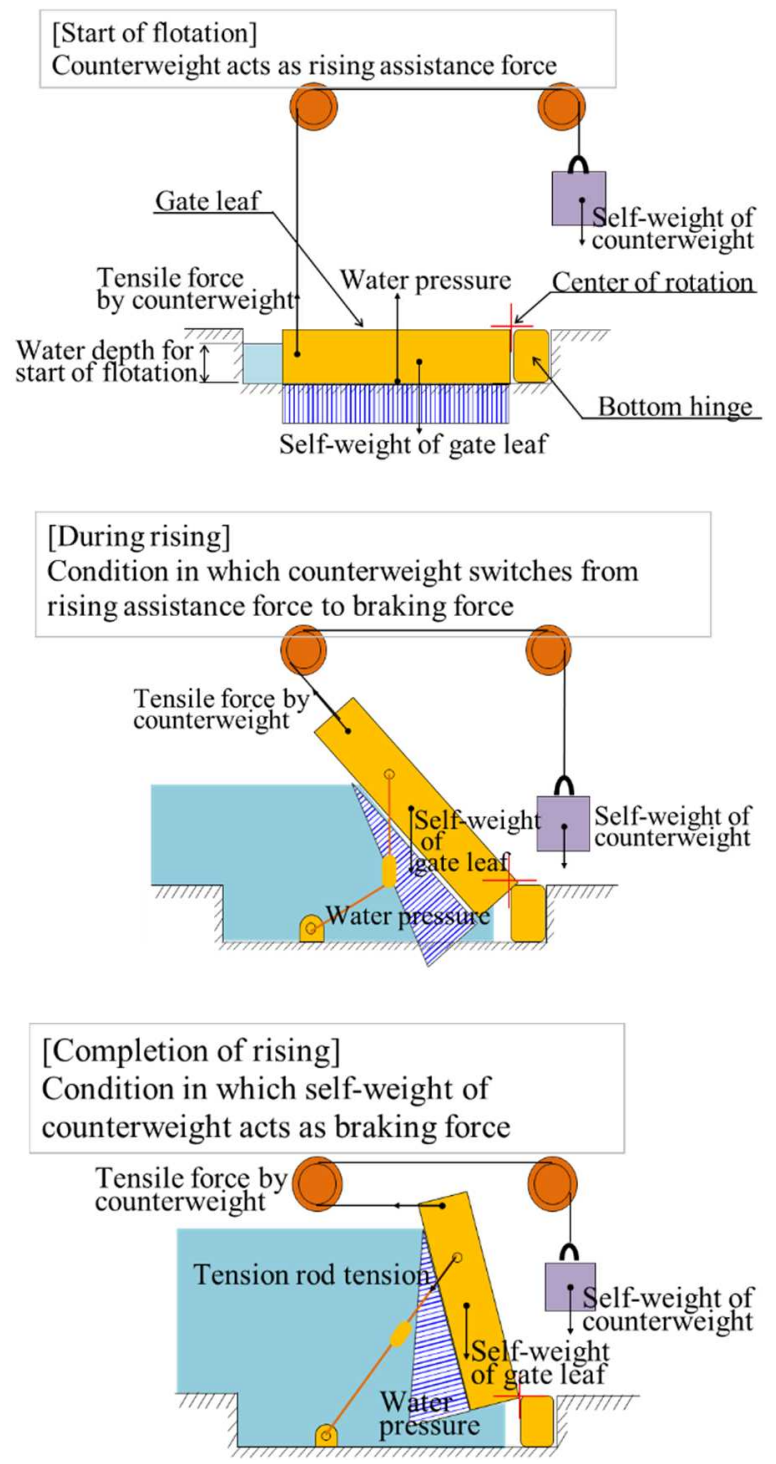

Fig. 6 Action of counterweight ${ }^{2}$. 
(4) Confirmation test of water-level followability, etc., using an actual gate

Next, this section describes a confirmation test of the water-level followability, etc., using the actual gate. As shown in Fig. 7, a temporary reservoir was constructed on the sea side of the flap-gate-type rising seawall and the relationship between the frontside water level and the rising angle of the gate was examined by filling the reservoir with water.

In addition, as shown in Fig. 8, the flotation water level of the gate leaf was examined by closing the water conduit/drainage equipment and filling it with water. Since it was difficult to find the exact water depth at which flotation of the gate started, the water depth when the gate rose $1 \mathrm{~cm}$ was examined. Those results are shown in Table 4. It can be understood that the flotation of the actual gate was approximately $1 \mathrm{~cm}$ faster than the design value. From this, it was found that the flotation performance of the actual gate exceeded the design performance.

Figure 9 shows a comparison of the results of both tests and the calculated values using the design values. Since the 0.95 of a sliding bearing was used as the efficiency index of the sheave in the design, the figure also shows the calculated value for the case of sheave efficiency of 0.95. A rolling bearing (mechanical efficiency: 0.98) was used in the actual device, and the result of a calculation assuming sheave efficiency of 1.0 is also shown, considering the fact that the flap-gate-type rising seawall had just been manufactured. The results of the test to confirm the water

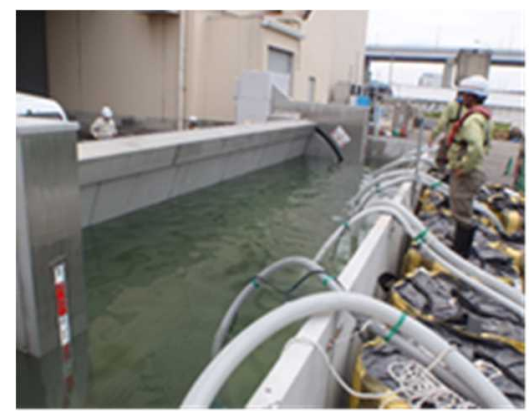

Fig. 7 Test to confirm water-level followability.

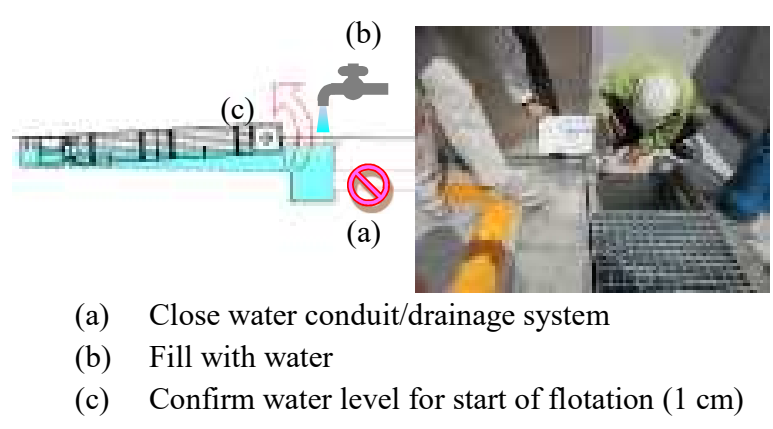

Fig. 8 Test to confirm water level for the start of flotation. depth for the start of flotation are also shown. Comparing the test results and the calculated values, the rising angle in the test results was approximately $10 \%$ larger than the calculated value using the values at the time of design. The calculated value for the sheave efficiency of 1.00 , which is considered to be closer to the actual condition, is also closer to the measured value. The overall tendency of the test results is consistent with the calculated values. This shows that the performance of the actual gate is rough as designed and the actual gate rises easier than calculated at the time of design. Based on these results, the gate can be expected to maintain the designed performance, even assuming the sheave efficiency of the actual device decreases by $10 \%$. Conversely, these results are also thought to suggest the possibility that the water-level followability of the gate may decrease to below the performance at the time of completion if the sheave efficiency of the actual device decreases to approximately $0.95 \times 0.9=0.855$. The results of the test to confirm the water level for the start of flotation are positioned to the lower left of a linear extension of the water-level followability test results and calculated values. As shown in Fig. 5, the moment of buoyancy decreases as the rise angle becomes smaller, and it is also known that the mechanical efficiency of sheaves displays the least efficiency at the start of the operation. Based on this, it can be understood that flotation is the most difficult at the start of flotation, when the rise angle is the smallest. Thus, it is suggested that a large-scale water-level followabil-

Table 4 Comparison of water level for the start of flotation.

\begin{tabular}{|c|c|c|c|}
\hline \multirow{2}{*}{ Test } & \multirow{2}{*}{$\begin{array}{c}\text { Rise } \\
\text { height } \\
\end{array}$} & $(\mathrm{cm})$ & \multicolumn{2}{|c|}{$\begin{array}{c}\text { Water level at start of } \\
\text { rise (G.L.) cm }\end{array}$} \\
\cline { 3 - 4 } & 1.0 & -6.5 & -7.5 \\
\hline 1 & 1.0 value & $\begin{array}{c}\text { Measure- } \\
\text { ment }\end{array}$ \\
\hline 2 & 1.5 & -6.2 & -7.5 \\
\hline 3 & 1.2 & -6.4 & -7.5 \\
\hline
\end{tabular}

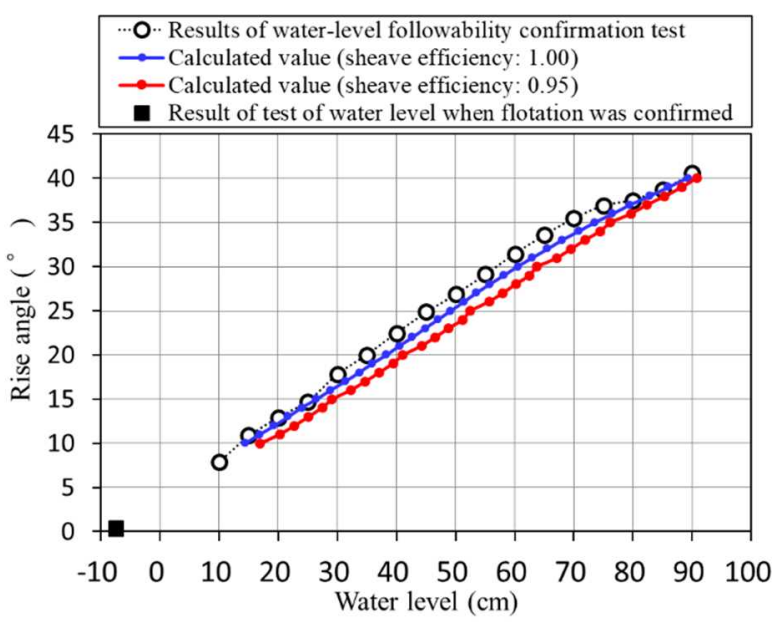

Fig. 9 Relationship of front-side water level and gate rise angle. 
ity confirmation test shown in Fig. 7 is not necessarily required, and the flotation performance of an actual gate can be comprehended by a test to confirm the water level for the start of flotation in Fig. 8. If calculated for the flap-gate-type rising seawall with a gate clear span of $8 \mathrm{~m}$ in the Muya Port Coast, about $5 \mathrm{~m}^{3}$ of water was needed to secure the water depth at which the gate leaf started to float. Therefore, the minimum equipment necessary for this test is a $2 \mathrm{t}$ truck, $4 \mathrm{t}$ truck (equipped with water tanks and generators), an underwater pump, sandbags, and the like. If the amount of water required is small, or an abundant supply of water is available, it is thought that the test to confirm the water depth for the start of flotation can be carried out with simpler equipment. In the test to confirm the water depth for the start of flotation of the flap-gate-type rising seawall with a $6 \mathrm{~m}$ clear span at the Muya Port coast, a $4 \mathrm{kl}$ class sprinkler truck was used, as the amount of water required for the test was less than $4 \mathrm{~m}^{3}$.

\section{(5) Measurement of gate deflection}

In the calculation of the deflection of the gate leaf at the time of design, in accordance with the method in the Technical Standards and Commentaries for Dams and Weirs (Draft), part of the skin plate (steel plate material used to secure the water-tightness of the gate leaf) is regarded as a flange of the horizontal main girder, and deflection is calculated assuming a simple beam. Although the loads acting on the gate leaves of general water gates are supported by the two (right and left) sides, the top horizontal girder of the flap-gate-type rising seawall at the Muya Port Coast is supported by the two sides, and the bottom horizontal girder is supported by the bottom hinge.

Therefore, the appropriateness of the design method was verified by comparing the calculated values of this design and the actual results of deflection by the action of water pressure. In the test, displacement gauges were installed so that their height would be almost the same as the filled water level, as shown in Fig. 10 when the gate leaf was raised to the fully upright condition. The deflection of the gate leaf was measured when the temporary reservoir was completely filled (i.e., water level of $1.0 \mathrm{~m}$ ). Those results are shown in Table 5. In Table 5, the deflection of the horizontal main girder at the water level at the time of deflection measurement is also shown as a measured value. As shown in Table 5, the measured value was substantially the same as the calculated value. This is considered to suggest that the effect of the bottom hinge on the deflection of the gate leaf is not particularly large. Therefore, the method of calculating the deflection of the main girders assuming a simple beam is considered to be generally appropriate.

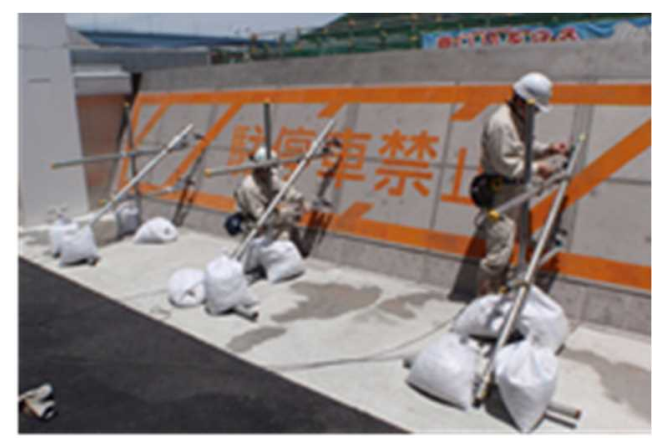

Fig. 10 Installation of displacement gauge.

Table 5 Results of measurement of deflection in water filling test.

\begin{tabular}{|c|c|c|}
\hline \multirow{2}{*}{ Test No. } & \multicolumn{2}{|c|}{$\begin{array}{c}\text { Maximum deflection } \\
\text { (center of gate leaf) }(\mathrm{mm})\end{array}$} \\
\cline { 2 - 3 } & Calculated value & Measured value \\
\hline 1 & \multirow{2}{*}{0.13} & 0.12 \\
\hline 2 & & 0.11 \\
\hline
\end{tabular}

\section{(6) Results of performance verification test}

The performance of the actual flap-gate-type rising seawall was examined by constructing a temporary reservoir and the results were compared with the values calculated with the values used in the design. The measured results were consistent with the calculated values in all cases. This suggests that the performance of an actual flap-gate-type rising seawall (i.e., flotation performance, water-level followability, and deflection) can be estimated by calculations utilizing the values used at the time of design. This actual flapgate-type rising seawall is the design example that became the basis for the establishment of the technical manual ${ }^{2}$. With these two points, following the technical manual ${ }^{2)}$, it is suggested that the performance of a flap-gate-type rising seawall can be calculated from the design results or the values used at the time of design, and a large-scale water-level followability confirmation test like that carried out at Muya Port is not necessarily required. In cases where sheave efficiency may decrease by $10 \%$ or more due to the age deterioration, it can be thought that gaterising performance will also decrease. Therefore, conducting a comparatively simple test to confirm the water depth for the start of flotation is considered effective for verification of flotation performance due to the age deterioration.

\section{SECURING RELIABILITY AND OP- ERATION AND MAINTENANCE}

As the function of preventing inundation by turning upright during a tsunami or storm surge is required in this facility, the conditions under which the flap-gate-type rising seawall will fail to rise were 
studied by using an event tree analysis. The cases assumed in general (motor-driven) landlocks are shown in the upper part of Fig. 11. Multiple causes of failure to close may be mentioned, including failure of structural parts, malfunction of mechanical devices, malfunctions of control devices, failure of drive power, human error by the operator, etc. In contrast, there are few causes of failure to close in the case of the flapgate-type rising seawall (lower part of the figure), as this type employs a mechanism in which the gate is turned upright by natural buoyancy and does not require drive force. Thus, the causes related to malfunction of mechanical or control system equipment, loss of drive power and human error (crossed out with the diagonal lines) do not exist in the flap- gate-type rising seawall.

As shown in Fig. 12, the possible causes obstructing rising were extracted and the policy for responding to those problems was studied. In parallel, the trial design of the flap-gate-type rising seawall in the Muya Port Coastal Protection Project was implemented, and problems were also studied at the level of members and parts. Many causes before the final event of "Gate does not rise" can be considered by arrangement in the form shown in Fig. 12. Although there are also problems that can be avoided in the design stage, it was found that the response for many items is ultimately proper operation and maintenance. Moreover, among the factors obstructing gate rising and their effects, various items that are not fully understood also remain to be clarified ${ }^{9)}$.

The following items were considered concretely in the design for the Muya Port Coastal Protection Project:

\section{a) Design to reduce the effect of ground defor- mation}

As introduced in Reference ${ }^{8)}$, a steel pipe pile foundation was adopted, and the structure was designed to reduce the inclination angle of the flap-
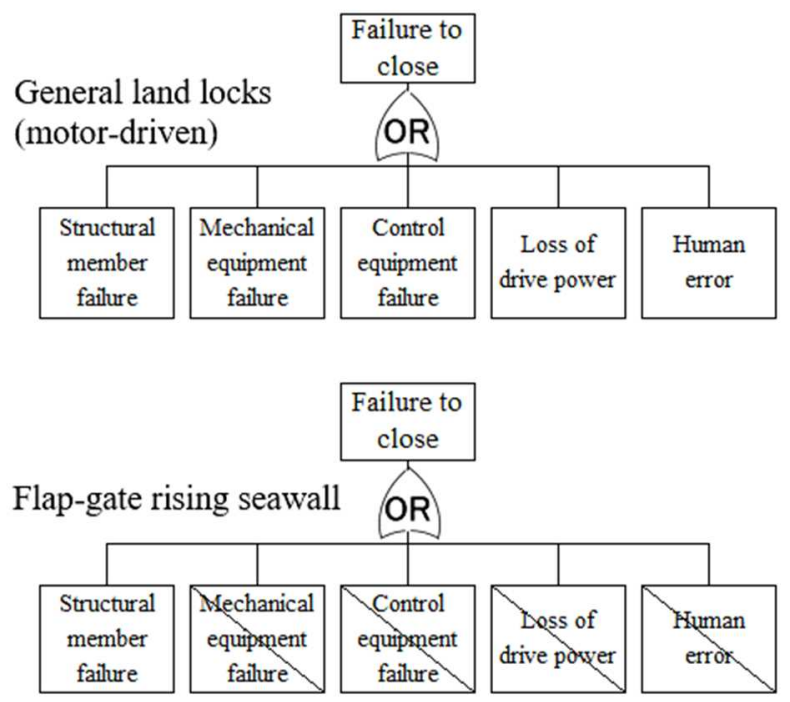

Fig. 11 Comparison of reliability (concept). gate-type rising seawall.

\section{b) Deformation by flotsam (drifting objects)}

Considering the impact loads caused by drifting objects based on Guidelines for Design of Countermeasure Facilities for Tsunami Wreckage ${ }^{11)}$, in the design of the gate leaf, tension rods were not installed, as they are considered to be affected easily by the impact of drifting objects.

\section{c) Design for easy maintenance and inspection}

On the outer walls of not the side of the sidewalls (i.e., side where the gate leaf is not attached), a bolted structure was used so that the outer side plates can be removed for inspections.

\section{d) Design to prevent rope detachment}

Guides were provided on the sheave in the sidewalls to prevent the wire rope from jumping and becoming detached from the sheave.

\section{e) Design to prevent the entry of foreign matter}

Unnecessary openings were not provided in the sidewall, and rubber covers were provided for slits on the sidewalls when unavoidably necessary.

\section{f) Design with margin in water conduit route}

The water conduit route was designed to have a margin of two times the design rainfall. In addition, the water conduit/drainage system was designed with a width that enables entry and easy removal of accumulated dirt by the worker's hands.

It was decided that many of these items would be checked by "Periodic operation checks," as shown in the response policy in Fig. 12.

Items, the effects of which are understood by hydraulic model experiments, will be considered in the design stage. In particular, a structure that considered hindering factors was adopted for "Structure enabling easy inspection work," etc.

In a fault tree analysis, the evaluation is generally carried out by assigning probabilities of event occurrence. However, the flap-gate-type rising seawall is a facility that must have both the function of allowing pedestrians and vehicles to pass under normal conditions and the function of rising automatically accompanying inundation during a tsunami or storm surge, and because the structure has newly developed functions and members, state probabilities are unknown at this stage. Therefore, data will be collected while the facility is in use and will be reflected in an appropriate operation and maintenance plan.

The effects of changes in the conditions of the component members/parts of the flap-gate-type rising seawall on decreased performance are shown in Fig. 13. Based on the arrangement in Fig. 12, the effects of changes in the flap-gate-type rising seawall were rearranged in four ranks (A to D), as shown in Table 6. In addition, an operation and maintenance plan was produced, supposing an inspection flow shown in Fig. 14, referring to manuals for similar 


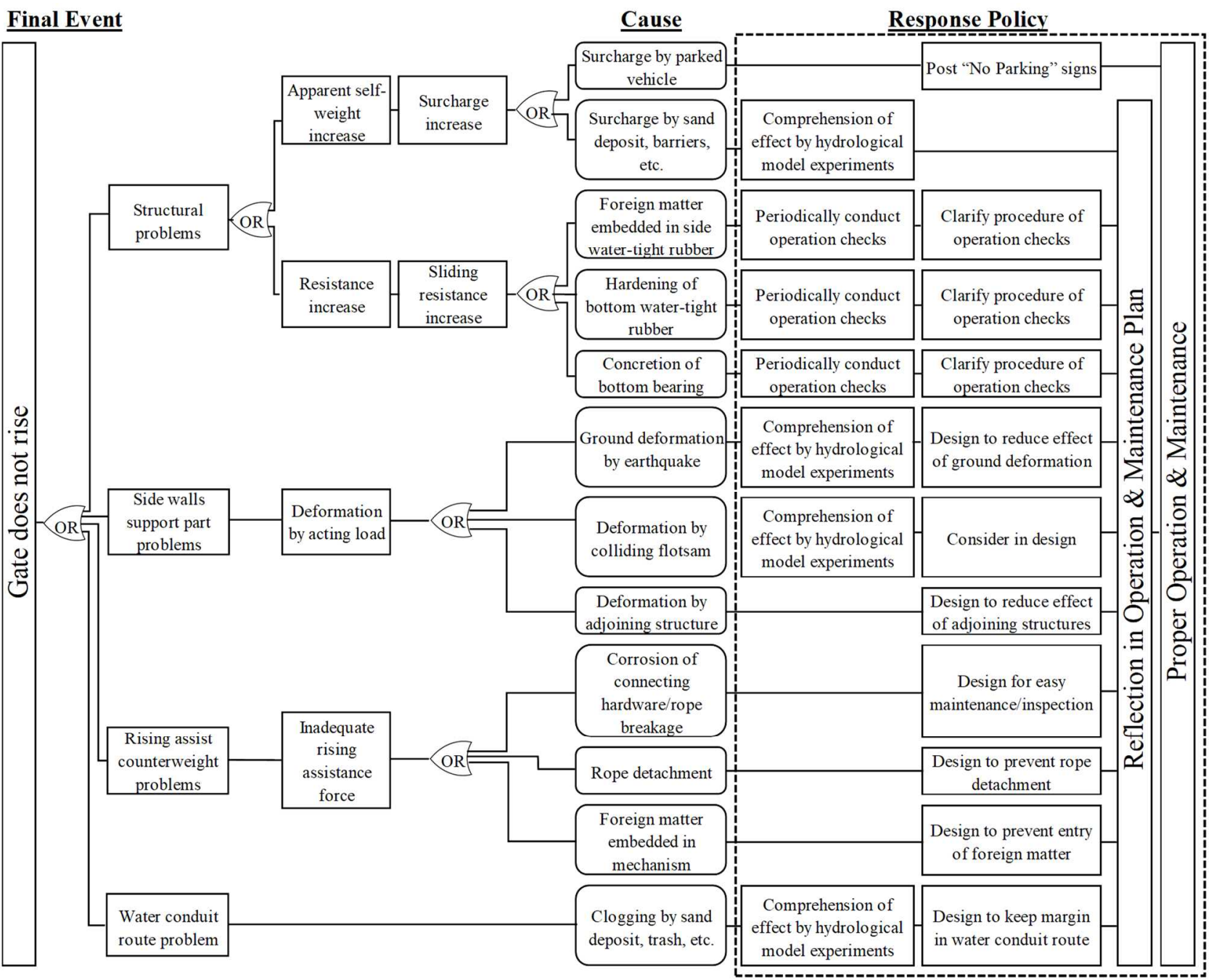

Fig. 12 Causes of gate failure to rise and policy for the response (Reference 10) with additions/revisions.

structures. At the present time, regular walk-around inspections are conducted approximately once a month. The results of these inspections are classified by the inspection point, type of inspection (routine walk-around inspection, periodic inspection, detailed inspection), and content, as summarized in Table 7. In Table 7, the $\bigcirc$ symbol indicates inspection items that are performed as standard procedures. Here, a $\Delta$ symbol is shown for "Stagnation of rainwater?" because this can be checked when rainfall occurs, etc.

Inspections of the flap-gate-type rising seawalls at the Muya Port coastline are conducted in accordance with Table 7. However, in the discussions that resulted in the production of Table 7, the highest priority in the maintenance of the flap-gate-type rising seawall was given to the certainty of operation, because operation and maintenance works of the flapgate-type rising seawall has just started. For this reason, it is possible that the content of Table 7 may be somewhat too conservative. Further improvement to realize a more appropriate and rational operation and maintenance plan is considered possible by accumulating data after the start of service, including the interval and setting of the frequency of regular walk- around inspections, standards for judging the necessity of special detailed inspections based on the results of visual inspections, etc. Moreover, concrete inspection items and inspection record formats were also prepared using the Muya Port Coastal Protection Project as a model case, both from the viewpoint of the convenience of operators who install flap-gatetype rising seawalls in the future, and for easy recordkeeping of maintenance results for a study of the more appropriate and rational operation and maintenance methods. Please refer to the examples of inspection items and the inspection record form shown in the Appendix.

\section{CONCLUSION}

This report has presented an outline of the design of the flap-gate-type rising seawall and its operation, maintenance, etc. When a protective function by a flap-gate-type rising seawall is considered necessary, reliable operation of the facility is expected to contribute to ensuring the safety of operators and disaster prevention and disaster mitigation in the region con- 


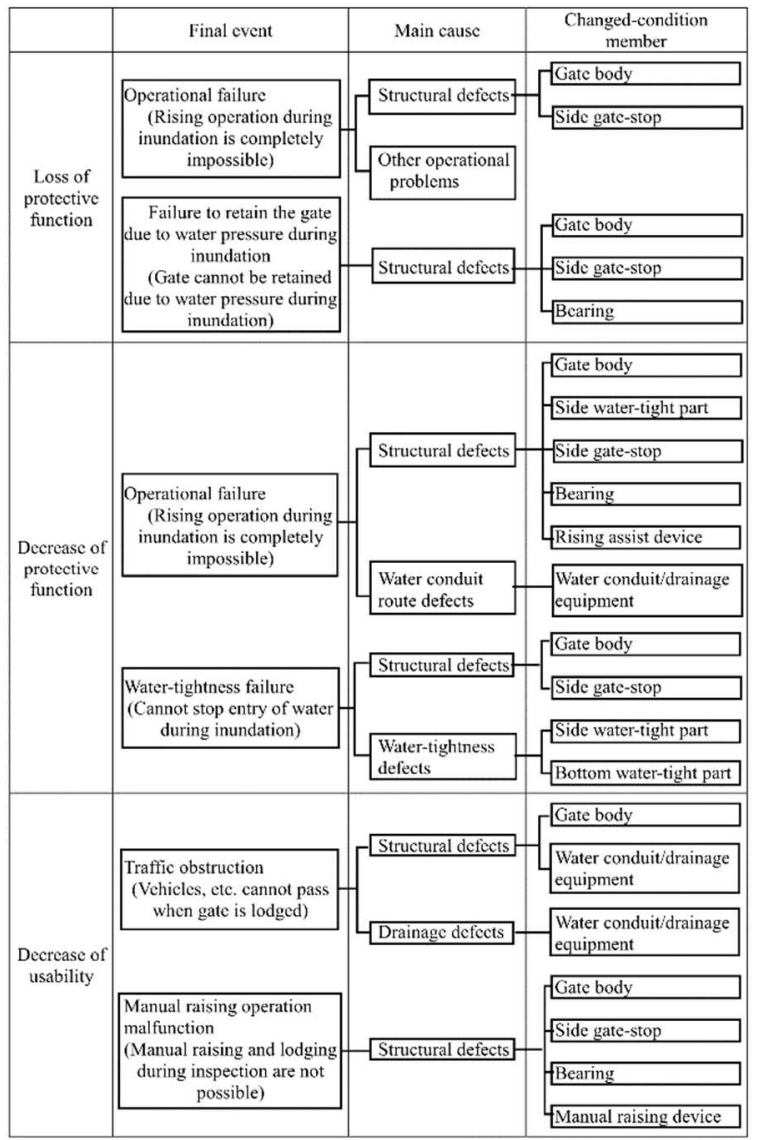

Fig. 13 Factors in decreased performance of flap-gate-type rising seawall.

cerned.

Unlike conventional flap-gate-type landlock, the flap-gate-type rising seawall described here has the function of allowing passage of pedestrians and vehicles under normal conditions, and must rise automatically when a tsunami or storm surge generates as well. Although this technology is still in the first stage of practical application at the Muya Port coast, the performance requirements, performance criteria, and verification procedures were organized in a performance design system. The directions for construction, operation, and maintenance were also presented and reflected in the "Technical Manual for FlapGate-Type Rising Seawalls" 2).

In addition, the results confirming the performance using the actual flap-gate-type rising seawall and calculated performance values using the values at the time of design were compared and it was shown that the performance of an actual flap-gate-type rising seawall could be inferred by a desktop study from the values used in the design process. Based on this, it is suggested that a performance test using a large-scale water reservoir is not necessarily required when a flap-gate-type rising seawall is to be introduced. Moreover, a comparison of reliability with conventional motor-driven landlocks showed that there were fewer factors that could cause failure to close in a
Table 6 Classification of effect degree by type of deformation.

\begin{tabular}{|c|c|}
\hline $\begin{array}{l}\text { Effect } \\
\text { degree }\end{array}$ & Definition \\
\hline A & $\begin{array}{l}\text { Deformation that greatly reduces the } \\
\text { protection performance of the facility }\end{array}$ \\
\hline \multirow[b]{3}{*}{ B } & $\begin{array}{l}\text { Deformation that reduces the protec- } \\
\text { tive performance of the facility }\end{array}$ \\
\hline & $\begin{array}{l}\text { Deformation that affects the passage } \\
\text { of vehicles }\end{array}$ \\
\hline & $\begin{array}{l}\text { Deformation that does not directly af- } \\
\text { fect the protection performance or } \\
\text { the passage of vehicles, but may pos- } \\
\text { sibly lead to abnormality in other } \\
\text { members by chain reaction. }\end{array}$ \\
\hline \multirow[t]{2}{*}{$\mathrm{C}$} & $\begin{array}{l}\text { Deformation that does not affect the } \\
\text { protection performance or the pas- } \\
\text { sage of vehicles, but can become the } \\
\text { cause of a serious abnormality if it } \\
\text { progresses. }\end{array}$ \\
\hline & $\begin{array}{l}\text { Cause of the abnormality is unknown } \\
\text { on the spot; separate investigation is } \\
\text { necessary. }\end{array}$ \\
\hline $\mathrm{D}$ & $\begin{array}{l}\text { Can be cleaned or removed immedi- } \\
\text { ately on the spot, such as dirt, foreign } \\
\text { matter, etc. }\end{array}$ \\
\hline
\end{tabular}

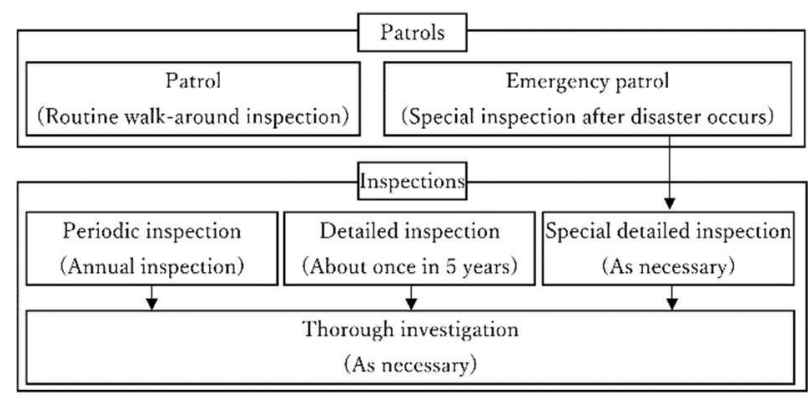

Fig. 14 Flow of operation \& maintenance plan.

flap-gate-type rising seawall. However, a fault tree analysis and diagram of factors in performance reduction indicated that operation and maintenance were important.

With these points, the flow of the operation and maintenance plan was established, and concrete inspection items and inspection record formats were prepared. Examples are presented in the Appendix of this paper. The results of this research are expected to contribute to the appropriate design, construction, operation, and maintenance of flap-gate-type rising seawalls in the future.

If you wish to use the items (in Japanese) that require attention in inspections, inspection record forms, etc., introduced in the Appendix, please inquire with the Takamatsu Research and Engineering Office, Shikoku Regional Development Bureau, Ministry of Land, Infrastructure, Transport and Tourism (MLIT). When inquiring by email, please also contact us by telephone, as emails may not be delivered in some cases. 
Table 7 Classification of inspection items for flap-gate-type rising seawall.

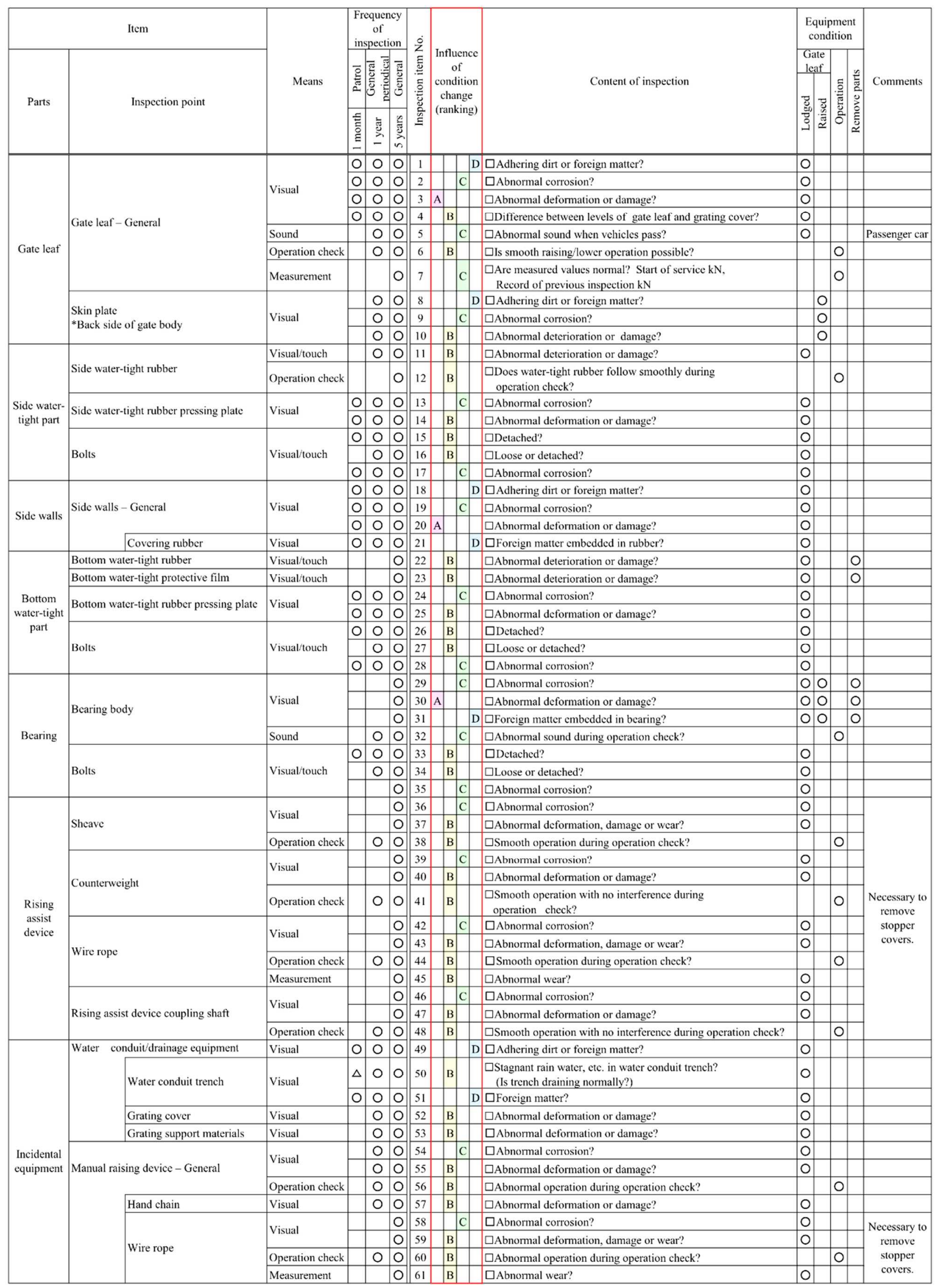


ACKNOWLEDGMENTS: In the installation of the flap-gate-type rising seawall in the Muya Port Coastal Protection Facilities Improvement Project, the Muya Port Coast Land Installation-Type Floating-Type Seawall Study Group chaired by Prof. Osamu Kiyomiya of the Faculty of Science and Engineering, Waseda University was established and the installation was carried out under the guidance of that group. We wish to express our deep appreciation to all the group members, beginning with the Chairperson, Prof. Osamu Kiyomiya of the Faculty of Science and Engineering, Waseda University. In this research, we received many useful suggestions from General Manager Kyoichi Nakayasu of the Flap Gate Department, Hitachi Zosen Corporation. We also received cooperation from Mr. Takahiro Sugano, Deputy Director General of the Coastal Development Institute of Technology in writing this report. We wish to take this opportunity to express our appreciation to all concerned.

\section{APPENDIX}

\section{(1) Points requiring attention in inspections of flap- gate-type rising seawalls}
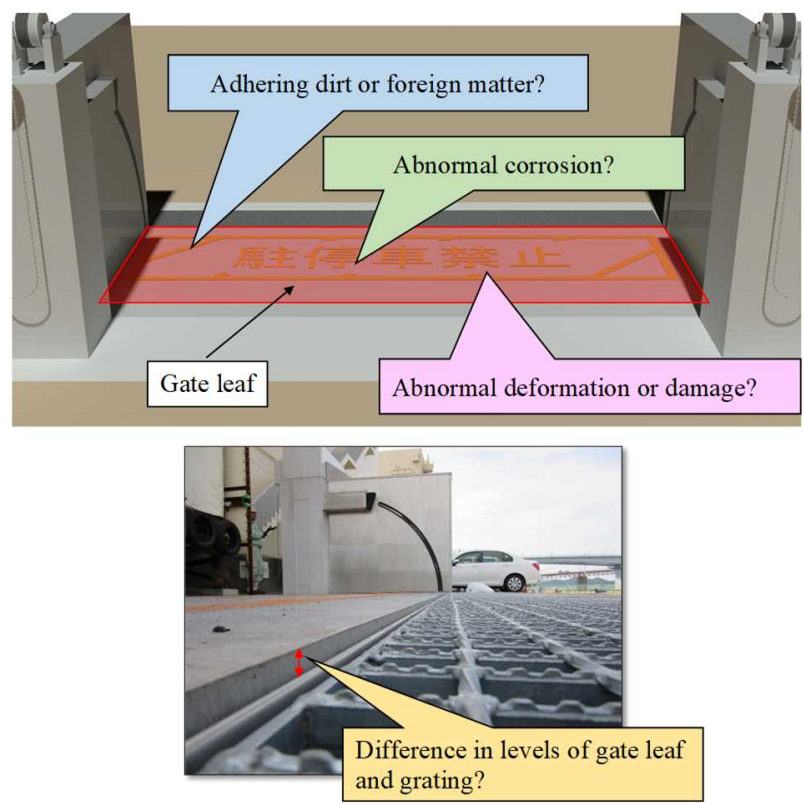

Fig. A1 Points in inspections of the gate leaf.
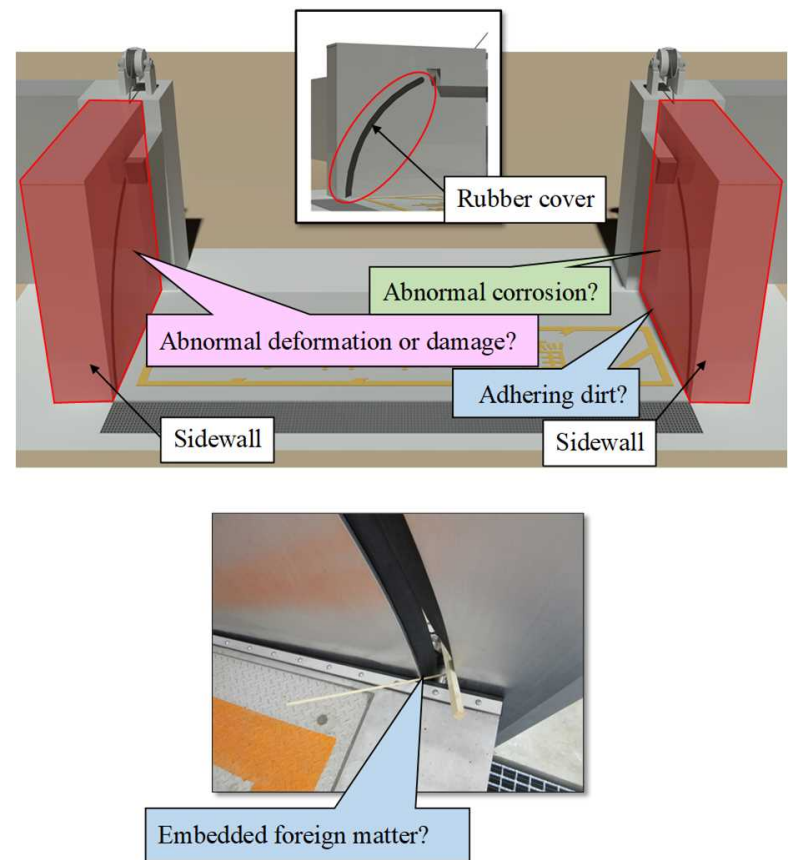

Fig. A2 Points in inspections of the sidewalls.

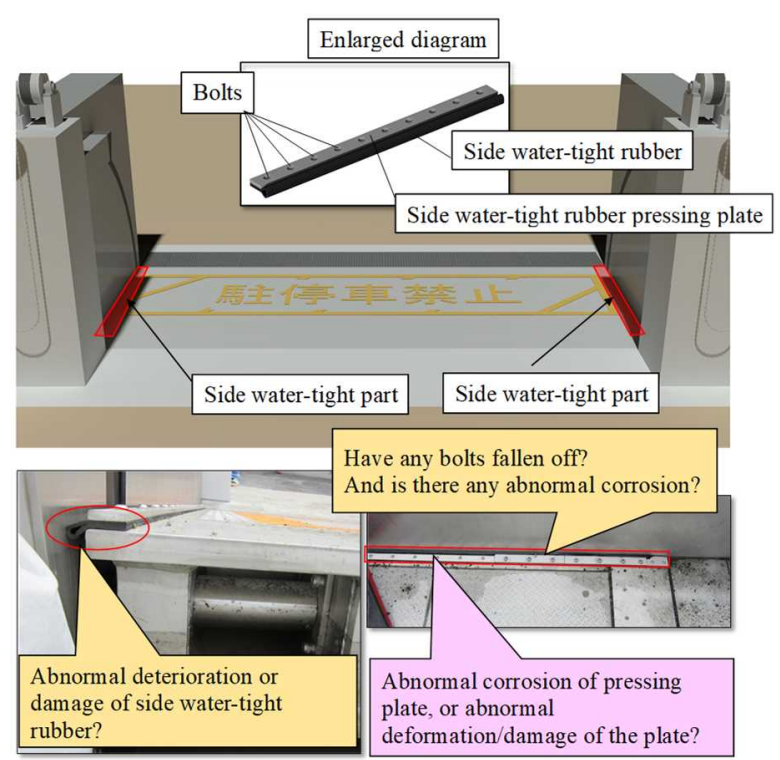

Fig. A3 Points in inspections of side water-tight part. 


\section{(2) Example of inspection record form}

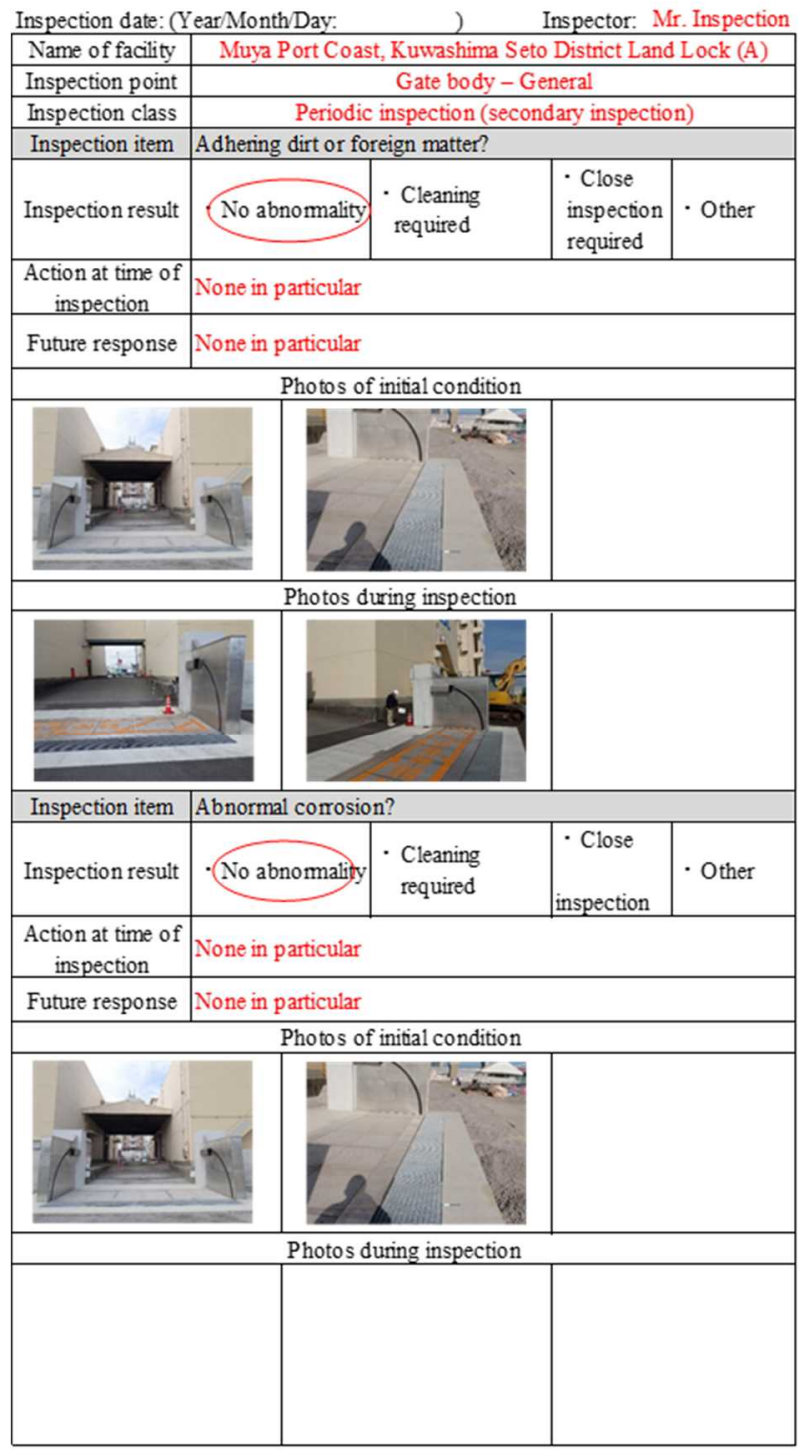

Fig. A4 Example of inspection record form.

\section{REFERENCES}

1) Mutual Aid Fund for Official Casualties and Retirement of Volunteer Firefighters : Status of public affairs disaster compensation for fire brigade members involved in the Great East Japan Earthquake (As of November 20, 2011), Study group on the ideal way of fire brigade activities at the time of a large-scale disaster based on the Great East Japan Earthquake (The first meeting document No. 13), 2011. (In Japanese)

2) Coastal Development Institute of Technology : Technical manual on flap-gate-type landlock for ports and coastal zones, Coastal Technology Library, No. 46, 2014. (In Japanese)

3) Japan Association of Dam and Weir Equipment Engineering : Technical standards for Dam and Weirs (Draft), 2013. (In Japanese)

4) Kimura, Y., Nakayasu, K., Morii, T. and Niizato, H.: Experimental verification on tsunami response of flap-gate-type landlock, Proceedings of the 65th JSCE Annual meeting, pp. 133-134, 2010. (In Japanese)

5) The coastal protection facilities technology research committee : Technical standards and commentaries for coastal protection facilities, 2004. (In Japanese)

6) The Ports and Harbours Association of Japan : Technical standards and commentaries for port and harbour facilities, 2007. (In Japanese)

7) Japan Association of Dam and Weir Equipment Engineering : Technical standards for Dam and Weirs (Draft), 2014. (In Japanese)

8) Takeda, A., Tomimoto, T., Arikawa, T., Okada, K. and Hirai, T.: Securing the performance of flap-gate-type landlock against inclination due to an earthquake, Proceedings of the 70th JSCE Annual meeting, II-182, pp. 363-364, 2015. (In Japanese)

9) Ito, Y., Yahiro, A., Koizumi, K. and Takagi, Y.: Technical issues and countermeasures for flap-gate-type landlock, Journal of the Coastal Development Institute of Technology, No. 13, 2013. (In Japanese)

10) Sano, M., Simosako, K., Nakayasu, K. and Yahiro, A.: Development, design and construction of flap-gate-type seawall for tsunami and storm surge, Journal of Civil Engineering, Vol. 57, No. 1, pp. 92-96, 2016. (In Japanese)

11) Coastal Development Institute of Technology and Cold Region Air and Sea Port Engineering Research Center : Guidelines for designing countermeasures against tsunami debris, 2014. (In Japanese) 